\title{
UCRL-CONF-154956
}

LAWRENCE LIVERMORE NATIONAL LABORATORY

\section{Multilayer Dielectric Gratings for Petawatt-Class Laser Systems}

J. A. Britten, W. Molander, A. M. Komashko, and C. P. J. Barty

December 3, 2003

Boulder Damage Symposium, Boulder, Colorado, September 22-24, 2003 
This document was prepared as an account of work sponsored by an agency of the United States Government. Neither the United States Government nor the University of California nor any of their employees, makes any warranty, express or implied, or assumes any legal liability or responsibility for the accuracy, completeness, or usefulness of any information, apparatus, product, or process disclosed, or represents that its use would not infringe privately owned rights. Reference herein to any specific commercial product, process, or service by trade name, trademark, manufacturer, or otherwise, does not necessarily constitute or imply its endorsement, recommendation, or favoring by the United States Government or the University of California. The views and opinions of authors expressed herein do not necessarily state or reflect those of the United States Government or the University of California, and shall not be used for advertising or product endorsement purposes. 


\title{
Multilayer Dielectric Gratings for Petawatt-Class Laser Systems
}

\author{
Jerald A. Britten, William Molander, Aleksey M. Komashko', Christopher P.J. Barty \\ Lawrence Livermore National Laboratory \\ Livermore, CA 94550 \\ a) now at General Atomics Photonics Div., San Diego, CA 92121
}

\begin{abstract}
Existing Petawatt class lasers today based on Nd:glass architectures operating at nominally $500 \mathrm{~J}, 0.5$ ps use meter-scale aperture, gold-overcoated master photoresist gratings to compress the amplified chirped pulse. Many lasers operating in the $>1 \mathrm{~kJ},>1 \mathrm{ps}$ regime are in the planning stages around the world. These will require multilayer dielectric diffraction gratings to handle larger peak powers than can be accommodated with gold gratings. Models of the electric field distribution in the solid material of these gratings suggest that high aspect-ratio structures used at high incidence angles will have better laser damage resistance. New tooling for transfer etching these submicron-grating patterns and for nondestructive critical-dimension measurement of these features on meter-scale substrates will be described.
\end{abstract}

Keywords: multilayer dielectric gratings, Petawatt lasers, chirped pulse amplification, reactive ion milling, atomic force microscopy

\section{INTRODUCTION}

Since the advent of the chirped-pulse amplification technique that enabled the realization of high-power picosecond and femtosecond laser systems ${ }^{12}$ these lasers have become essential tools for the study of matter under extreme-field conditions. The first Petawatt-class laser was built at LLNL in the mid $90^{\prime} \mathbf{s}^{3}$. It was based on Nd:glass at $1053 \mathrm{~nm}$, and produced $\sim 500$ Joules at $\sim 500 \mathrm{fs}$. Today, there are two such laser systems in operation ${ }^{4,5}$ and several more are being built or planned around the world. These laser systems, as well as others operating at lower pulse durations, are based on gold-overcoated holographic master gratings for the pulse compression elements. The limitations of metal-coated optics for high peak and average power handling capability led to the development of multilayer dielectric (MLD) gratings at LLNL in the mid $90^{6-8}$. This type of grating is now beginning to replace gold in high-energy and high-average power applications'. The need for large-aperture gratings for short-pulse capability on large-scale fusion lasers such as LLNL's National Ignition Facility, The Omega upgrade at the University of Rochester, the Z-Beamlet machine at Sandia National Laboratory, and several other facilities around the world, has led to efforts to phase several gratings to obtain a singleeffective aperture ${ }^{10}$, as well as the development of tooling and processes at LLNL for fabricating monolithic MLD gratings at $\sim 1$ meter aperture, leveraging our unique existing capability to fabricate gold-overcoated master gratings at this scale.

\section{DESIGN OF MLD GRATINGS}

Modeling of the electric field distribution in the vicinity of a high diffraction-efficiency grating illuminated by a coherent plane wave shows periodic maxima set up by interference between the incident and diffracted waves. Figure 1 shows such a distribution for a model grating. The high e-field penetrates into the solid material comprising the grating along the back side of the grating, as referenced from the side of the incoming wave. Field enhancements in these 'hot' zones are invariably greater than unity, normalized to the field strength of the incoming wave. Field enhancements this large are not typically seen in the solid material of a multilayer high-reflector, for example, so we expect the damage characteristics to be different between multilayer mirrors and MLD gratings. Stuart et al. " have published data on the damage characteristics of MLD gratings that show damage localized to the back edges of the grating ridges, in correspondence with model results (see Fig. 1). 

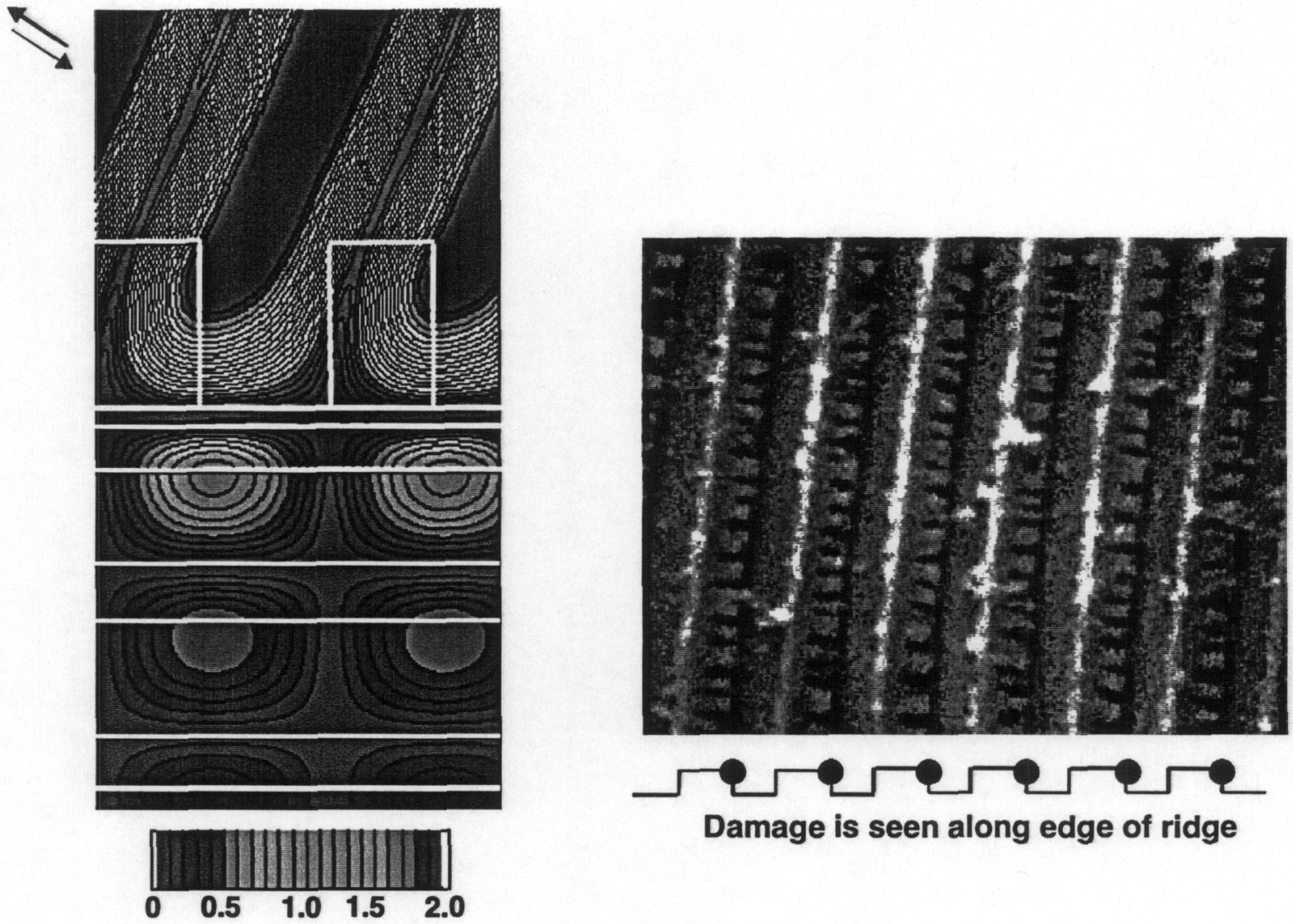

Figure 1, A. (Left); Distribution of electric field in the vicinity of a grating with laser radiation incident from the left.

Material interfaces Shown in white outline. B (Right); Scanning electron micrograph showing damage along back edge of grating ridges. (from Ref 11 ).

Our MLD grating design criteria seeks to minimize the electric field existing in the solid grating material, while at the same time maximizing the efficiency. Figure 2 shows a plot of the calculated diffraction efficiency at $1053 \mathrm{~nm}, 76.5^{\circ}$ incidence angle and TE polarization, of a 1780 line/mm MLD grating as a function of grating height on the vertical axis and grating duty cycle on the horizontal axis, for a $\mathrm{HfO}_{2} / \mathrm{SiO}_{2} \mathrm{MLD}$ grating with the grating in the top $\mathrm{SiO}$ layer. A surface of high efficiency $>99 \%$ extends from the lower right to the upper left of this plot, as shown. It is generally true that the electric field strength in the solid material along a line of constant diffraction efficiency decreases as the grating height becomes greater and the duty cycle smaller. Gratings with calculated electric field enhancements of $\sim 1.1$ are possible with manufacturable designs having duty cycles of $\sim 25 \%$ and height:width aspect ratios of $\sim 5: 1$. There has been speculation that such features may be more fragile to shock or ablative phenomena associated with the onset of damage, than stouter-looking designs having a higher intrinsic e-field. At present, there is insufficient evidence, considering the variability of witness designs and other potential causes of laser-induced damage such as contamination etc., to offer a definitive conclusion of the effect of grating shape on laser damage.

It is known, however, that increasing the incidence angle has a large effect on laser damage threshold. This may again be related to local electric field enhancement, more so than just the geometric effect of spreading the laser energy over a larger area. Figure 3 shows the measured laser damage threshold reported as a normal-incidence fluence, of a $18001 / \mathrm{mm}$ MLD grating at $1053 \mathrm{~nm}, \sim 10 \mathrm{ps,} \mathrm{TE} \mathrm{polarization,} \mathrm{as} \mathrm{a} \mathrm{function} \mathrm{of} \mathrm{incidence} \mathrm{angle.} \mathrm{The} \mathrm{damage} \mathrm{test} \mathrm{facility} \mathrm{used} \mathrm{the}$ output pulses from the regenerative amplifier of LLNL's COMET laser ${ }^{12}$ at nominally $1.5 \mathrm{~ns}, 10 \mathrm{~Hz}$, and $1.3 \mathrm{~mJ}$, which was compressed in a $1740 \mathrm{l} / \mathrm{mm}$, single grating two-pass compressor, set up to give a nominal 1 ps pulse duration. The 

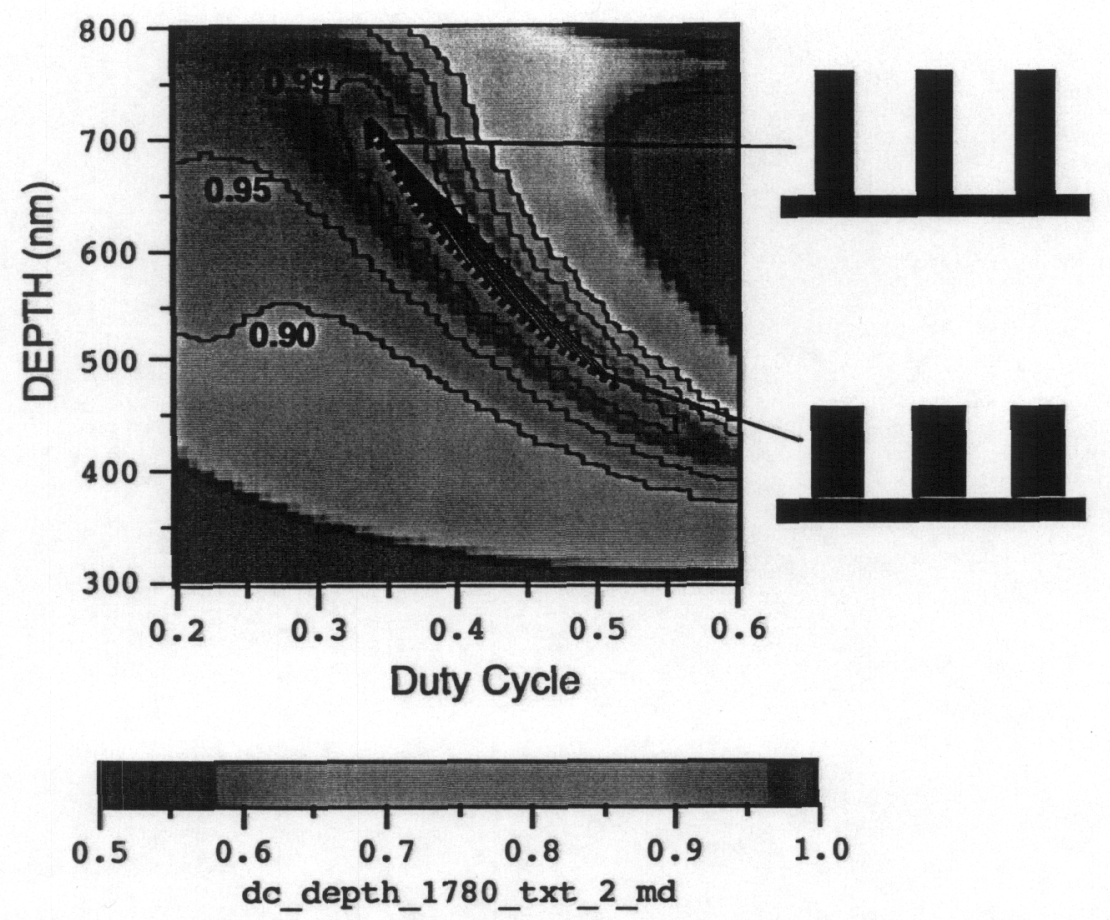

Figure 2. A plot of calculated diffraction efficiency as function of grating height and duty cycle for a 1780 line/mm MLD grating for $1053 \mathrm{~nm}$, TE polarization, $76.5^{\circ}$ incidence angle. For a given efficiency, maximum electric field in the solid grating material decreases in the direction of the arrow from lower right to upper left along dotted line.

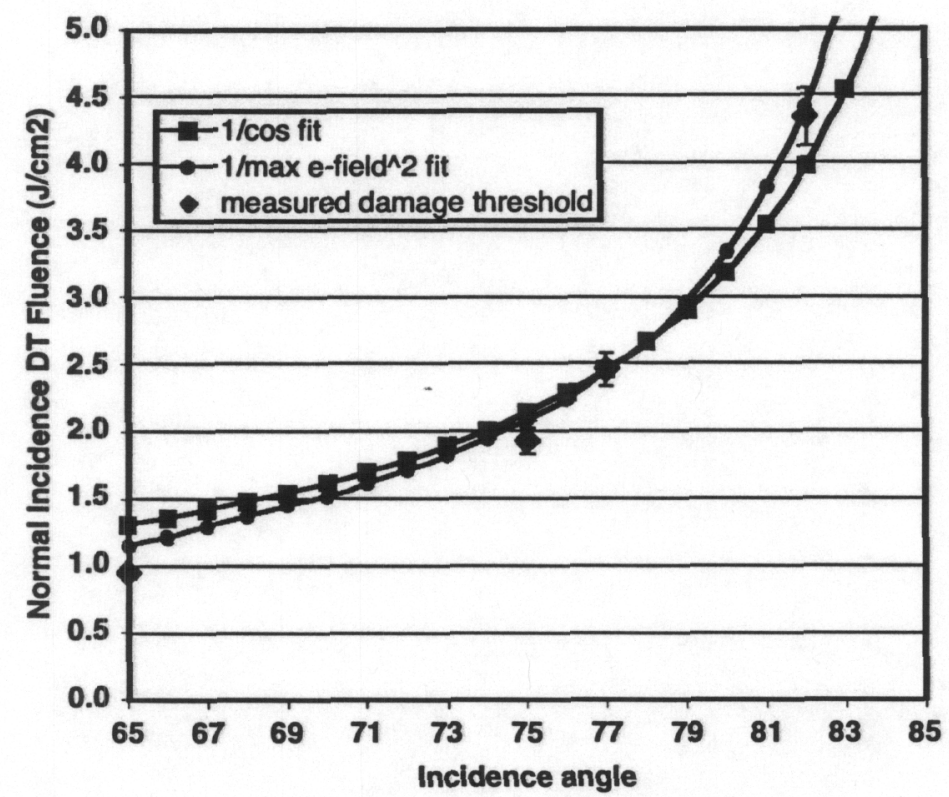

Figure 3. Measured laser damage threshold at $1053 \mathrm{~nm}$, TE polarization, $\sim 1$ ps pulse duration, of a $18001 / \mathrm{mm}$ grating as function of angle, plotted along with $1 / \cos$ projected area dependence and calculated square of the maximum e-field for this grating profile, both normalized to the measured value at $77^{\circ}$. 
pulse train was focused on the sample with a $1 \mathrm{~m}$ focal length lens. After several hundred shots on a site, the sample was examined using Nomarski microscopy to determine the fluence for the onset of damage, reported in this figure as a value at normal incidence.

The lack of adequate diagnostics for the temporal pulse characteristics of this damage test setup results in some uncertainty in the reported pulse duration. The actual damage fluence and the effect of incidence angle were reproducible and clearly defined, however. The microstructure of this sample grating, as measured by atomic force microscopy, was used in a model calculation of the e-field enhancement as a function of angle. The square of the maximum e-field in the solid material was normalized to the measured damage threshold at $77^{\circ}$, and plotted in the figure. Also shown is the $1 / \cos$ area projection effect, again normalized to the measured threshold at $77^{\circ}$. Although the difference is not overly large, the measured damage fluence data fit the e-field enhancement curve better than the simple projected-area curve. This result clearly indicates that a modest increase in incidence angle, from 75 to $77^{\circ}$, for example, can increase the energy onto the grating by $>25 \%$ while increasing the long dimension of the grating by $15 \%$.

High-aspect grating structures used at high incidence angles make extreme demands on the manufacture of such optics, because it is more difficult to pattern and transfer-etch these types of features, and higher incidence angle translates into larger grating size. In the past year we have made two critical advances in tooling required to manufacture meter-scale, submicron-pitch, high-aspect ratio grating structures. We have designed and built a unique ion beam etcher, and have fielded a large-aperture atomic force microscope for critical in-process metrology of such gratings. These are described in the following sections. We now have a complete set of tooling required to fabricate meter-scale gratings and are beginning integrated testing.

\section{ADVANCES IN REACTIVE ION MILLING CAPABILITY}

A prototype linear ion source was procured from Veeco Ion Tech Inc., and a custom-etching tool was built around it. The source is powered by $13.56 \mathrm{MHz} R F$ at $2 \mathrm{~kW}$ and produces a collimated ion beam $1.1 \mathrm{~m}$ long and $6 \mathrm{~cm}$ wide. Three stainless steel vacuum chambers from LLNL's mothballed Atomic Vapor Isotope Separation Facility, each $1.8 \times 1.5 \times 0.6$ $\mathrm{m}(\mathrm{LxHxW})$ were joined to form one continuous chamber. The ion source was mounted vertically into a modified door of the center chamber, and a linear motion track was mounted along the floor to translate the substrate back and forth across the beam. A photograph of the tool during installation is shown in Figure 4. The chamber is capable of $8 \times 10^{-7} \mathrm{mmHg}$ vacuum during pumpdown, and is plumbed for three gases, argon, oxygen and a Freon compound for fluorine-based reactive chemistry for enhanced etching selectivity of oxide to mask material.

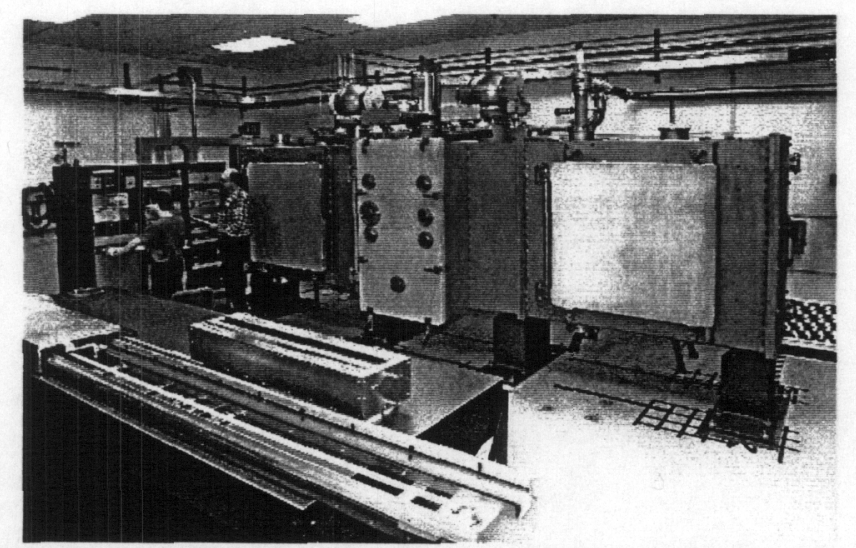

Figure 4. Reactive Ion Mill designed and constructed at LLNL for manufacture of submicron-pitch grating structures of up to $1 \mathrm{x} 2$ meters in aperture. Ion source and substrate linear motion track are in foreground awaiting installation

The uniformity of the etched pattern is related to the uniformity of the ion beam, which provides reactive gases and energetic ions that impinge upon the substrate and remove material. The beam uniformity varies over the length of the source mainly because of non-uniformities in the RF power emission. This can be improved by optimal distribution of the gas flow rates over the length of the source, adjustment of the total system pressure, and by placement of partial grounding plates to attenuate the RF power locally along the length of the source. 
A scanning Faraday cup current probe was built to characterize and optimize the ion beam uniformity. This probe consists of a grounded stainless steel housing with a slotted aperture $20 \mathrm{~cm}$ wide by $0.75 \mathrm{~cm}$ high to allow the ion beam to impinge upon the carbon electrode mounted inside. This electrode is connected electrically to the beam control module, which applies a bias voltage and displays the current measured. All materials in the probe assembly are vacuum compatible and bake-able. The probe is mounted on a computer-controlled stage that provides vertical motion to scan the probe in the ion beam. The stage and probe are in turn mounted onto the substrate transport system, which allows for horizontal positioning and scanning.

A number of experiments were performed varying the gas pressure and distribution, RF attenuator position, and acceleration and beam voltages, with the aim of optimizing the vertical distribution of the ion current. The horizontal etch rate is controlled by the constant velocity of the substrate carriage as it traverses the ion beam. As a proof-of-principle test of the optimized full-scale etching process, an $81-\mathrm{cm}$ round window glass substrate was coated on site with approximately $300 \mathrm{~nm}$ of $\mathrm{Ta}_{2} \mathrm{O}_{5}$ and etched. Window glass was used to reduce costs, and $\mathrm{Ta}_{2} \mathrm{O}_{5}$ was chosen because it etches with the same chemistry as $\mathrm{SiO}_{2}$ and the high index contrast between it and the window glass allows for inexpensive and fast interferometric measurements of the film thickness. The thickness of the $\mathrm{Ta}_{2} \mathrm{O}_{5}$ layer was measured at $2.5 \mathrm{~cm}$ intervals along the $\mathrm{x}$ and $\mathrm{y}$ axes of the substrate at its midpoint, before and after the etch run. The run was planned to remove approximately half the deposited film. The difference in the film thickness, representing the amount of etched material, is plotted in Figure 5. Horizontal etch depth uniformity is less than $3 \%$ absolute over $80 \mathrm{~cm}$. The vertical nonuniformity of $\sim 6 \%$ absolute agrees well with the vertical distribution of the ion current as measured with the scanning Faraday cup. Grating designs utilizing an etch-stop layer will not exhibit a measurable difference in etch-depth under these conditions.

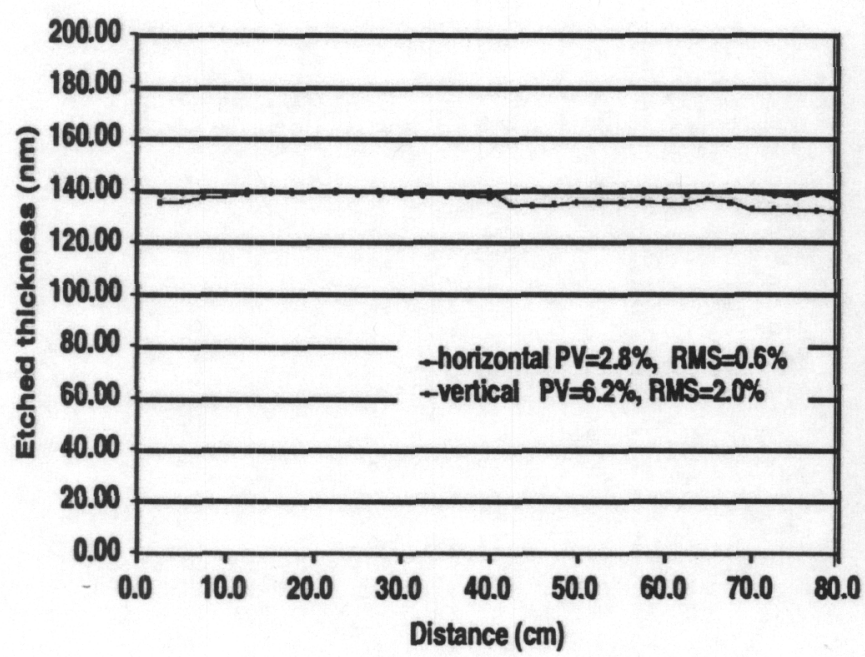

A

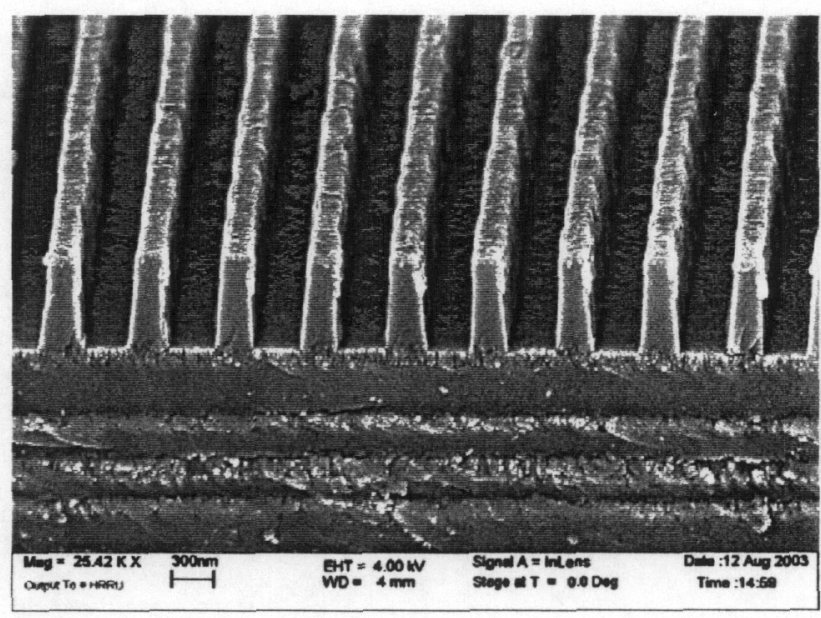

B

Figure 5. A (left). Measured etched depth of Ta2O5 film on taken on horizontal and vertical lineouts of $81 \mathrm{~cm}$ diameter coated window glass processes in linear ion-beam etcher. Peak-to-valley (PV) and standard deviation of etched thickness given in the figure body. B right). Scanning electron micrograph of section of 2 in. diameter 1740 line/mm witness grating processed in this tool. Grating is etched into $650 \mathrm{~nm} \mathrm{SiO} 2$ layer atop a $100 \mathrm{~nm} \mathrm{Al} 2 \mathrm{O} 3$ etch-stop layer.

Initial etching experiments on witness multilayer dielectric gratings have begun. The right image of Figure 5 shows a scanning electron micrograph of a 1740 line/mm MLD grating etched into a $700 \mathrm{~nm}$ thick $\mathrm{SiO}_{2}$ top layer. Based on current removal rates, a grating $80 \mathrm{~cm}$ in long aperture could be transfer-etched to completion in approximately 9 hours under these conditions. Experiments to develop trim-etch and resist stripping processes are ongoing. 


\section{ADVANCES IN METROLOGY CAPABILITY}

Tooling for full-aperture measurement of diffracted wavefront and diffraction efficiency of $1 \times 0.4$ meter diffraction gratings have existed for some time at LLNL and vendor facilities. However, in-process, non-destructive measurement of grating profiles is essential for MLD grating fabrication. Metal-overcoated gratings can be stripped of their coating and reprocessed if specifications are not met, but MLD gratings must be sent back for repolish in this case. We have recently installed and qualified a very-large atomic force microscope (AFM) capable of submicron-linewidth metrology over apertures of 1 meter square. A photograph of this tool is shown in Figure 6, along with a profile of a witness grating measured with it.
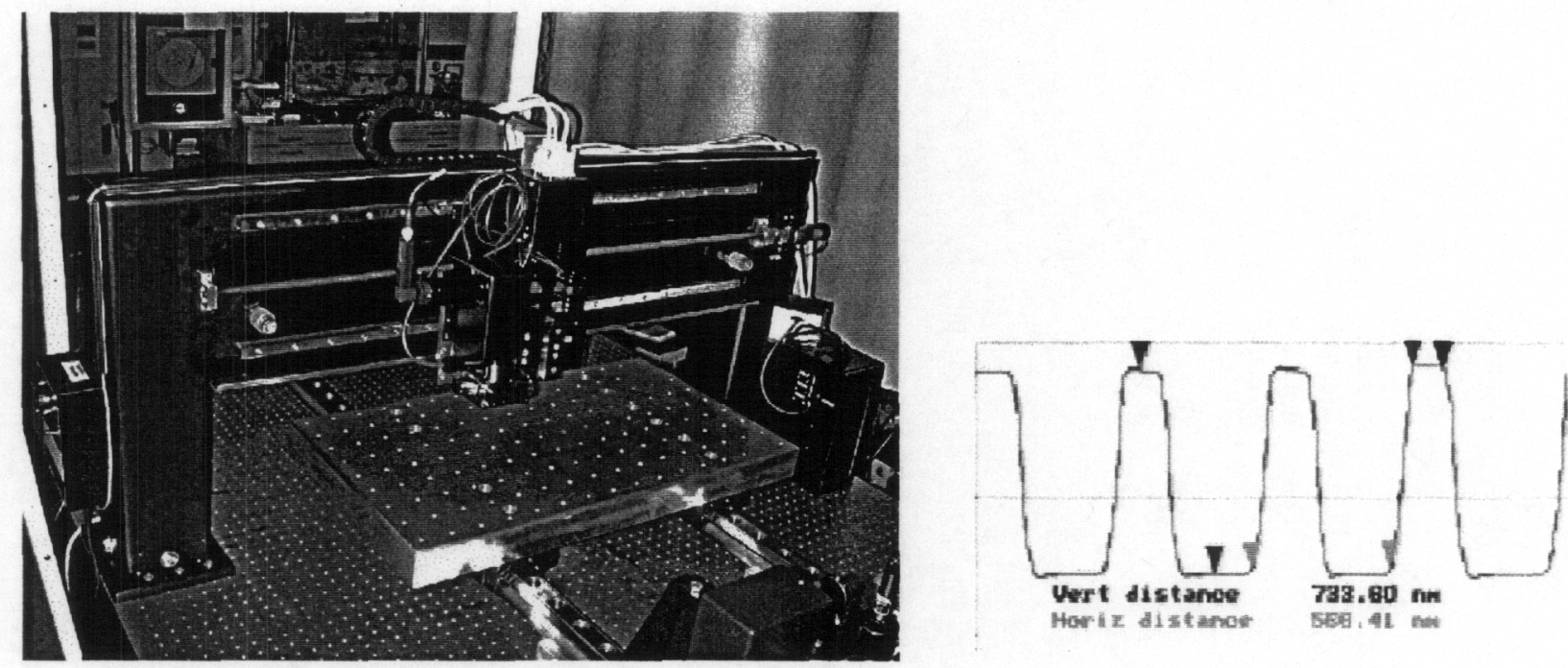

Figure 6. A (left). Atomic force microscope capable of measuring submicron-critical dimensions on grating substrates 1 meter wide and $15 \mathrm{~cm}$ thick. B (right): AFM trace of grating features at center of instrument.

\section{CONCLUSIONS}

Modeling of the electric field distribution in a high-efficiency MLD grating shows that fields in the solid grating material are lower for high height-to-width aspect ratios. Laser damage thresholds increase with increasing incidence angle for these gratings, in agreement with model predictions on angle-dependence of e-field distribution. We have designed, constructed and fielded a unique ion beam etcher capable of transfer-etching submicron grating features into optics as large as $2 \times 1$ meter, and now have the capability to image these features nondestructively on $\sim 1 \times 1$ meter substrates using atomic force microscopy.

Acknowledgements: The authors acknowledge the contributions of Les Jones, Tom Carlson, and many others for the design and construction and characterization of the ion mill. This work was performed by the University of California under the auspices of the U.S. Department of Energy under contract no. W-7405-Eng-48(LLNL) .

\section{REFERENCES}

1. D. Strickland and G. Mourou, 'Compression of amplified chirped optical pulses', Opt. Commun. $56,219-221,(1985)$

2. M.D. Perry and G. Mourou, 'Terawatt to Petawatt Subpicosecond Lasers' Science, 264, 917-924, (1994)

3. M.D. Perry, D. Pennington, B.C. Stuart, G. Tietbohl, J.A. Britten, C. Brown, S. Herman, B. Golic, M. Kartz, J. Miller, H.T. Powell, M. Vergino and V. Yanovsky, 'Petawatt Laser Pulses', Optics Letters, 24, 160-162, (1999) 
4. H. Fujita, Y. Kitagawa, T. Kawaski, S. Matsuo, H. Yoshida, R. Kodama, T. Jitsuno, K. Tsubakimoto, K, Shigemori, Y. Izawa, 'Peta-watt Laser for Fast Ignition Research at ILE, Osaka', JAERI Symposium on Control of Lasers for Strong Field Phenomena, Kyoto, Japan, Sept 12-13, (2002)

5. C.N. Danson, D. Neely, B.E. Wyborn, 'Vulcan Petawatt Upgrade Overview', Central Laser Facility Annual Report 2002/2003. CCLRC Rutherford Appleton Laboratory Report RAL-TR2003-018 (ISBN 0909376268), (2003). Available at http://www.clf.rl.ac.uk/Reports/20022003/contents.htm

6. M.D. Perry, J.A. Britten, H.T. Nguyen, R.D. Boyd, B.W. Shore, 'Multilayer Dielectric Diffraction Gratings', U.S. Patent no. 5907436, (1999)

7. M.D. Perry, R.D. Boyd, J.A. Britten, D. Decker, B.W. Shore, C. Shannon, E. Shults, and L. Li, 'High Efficiency Multilayer Dielectric Diffraction Gratings', Optics Letters, 20, 940-942, (1995)

8. B.W. Shore, M.D. Perry, J.A. Britten, R.D. Boyd, M.D. Feit, H. T. Nguyen, R. Chow, G. Loomis and $\mathrm{L}$. Li, 'Design of high-efficiency dielectric reflection gratings' Journal of the Optical Society of America A, 14, 1124-1136, (1997)

9. J. A. Britten, S.J. Bryan, L.J. Summers, H.T. Nguyen, B.W. Shore, and O. Lyngnes, 'LargeAperture, High-Efficiency Multilayer Dielectric Reflection Gratings' OSA Conference on Lasers and Electro-optics, Long Beach, CA, Postdeadline paper, May 23, 2002

10. T.J. Kessler, J. Bunkenburg, H. Huang, A. Kozlov, and D.D. Meyerhofer, 'Demonstration of coherent addition of multiple gratings for high energy chirped-pulse-amplified lasers", Optics Letters, submitted (2003)

11. B.C. Stuart, M.D. Feit, S.M. Herman, A.M. Rubenchik, B.W. Shore, M.D. Perry, 'UltrashortPulse Optical Damage' Laser-Induced Damage in Optical Materials, $27^{\text {th }}$ Boulder Damage Symposium, H.E. Bennett et al., eds, Proc. SPIE V2714, 616-627, (1995)

12. A description of LLNL's comet laser can be found at http://wwwphys.llnl.gov/Research/B174LaserFacility/Comet/comet_home.html 